\title{
Which Lenses Best Help us Make our Practices Inclusive?
}

Jenny Marie, Steve Rowett, Sally MacKenzie, Moira Wright, Sandra Lusk, University College London (UCL)

\section{Introduction}

The importance of inclusive practice is well recognised across the Higher Education sector, but how do we best consider how to make our practices more inclusive?

We can focus on the characteristics of students who face barriers to participation or on the characteristics of the provision that creates barriers. We can look through the lens of unengaged students or 'hard to reach' groups, engaged students in the latter having overcome barriers to participate. We can consider whom the provision was designed for and whether that disengages others.

In this opinion piece, we draw on staff interviews reported on elsewhere in this issue (Marie et al, 2017) to argue that it is important to consider both characteristics of students and the provision that can make them 'hard to reach'. We believe that the concept of 'hard to reach' groups is useful for identifying potential barriers. Whilst it is useful to consider whom provision is designed for and whether that is appropriate, we also need to recognise that the students it is designed for may still face significant barriers to engaging with it.

\section{Focus on the individual or the institution?}

A number of the staff we interviewed argued that the focus of inclusive practice should be on the institution, as that is what needs to change to become more inclusive, not the students. Whilst we fully agree that it is the institution that needs to change, we believe that focusing solely on the institution will not provide sufficient information about what needs to change. When the staff spoke of UCL creating barriers, they spoke of its size making community-building difficult, its position in London making it expensive and its Russell Group status alienating working-class students. An often over-looked factor is the time-poor nature of some of UCL's students, UCL's assumption that all students think and behave like undergraduates and the alienation of groups of students because the curriculum reflects white, western, male, heterosexual thinking.

\section{Unengaged or 'Hard to Reach'?}

One interviewee argued that we should use the terms 'unengaged' or 'disengaged' rather than 'hard to reach' because the latter shifts the blame to students. However, there is a difference. Unengaged students are not participating in a particular activity; 'hard to reach' students belong to a low participation group for the activity but may themselves be participating. In our opinion, there are two difficulties with focusing on unengaged students rather than 'hard to reach'. The first is that it is difficult to obtain information from unengaged students about why they are unengaged and what could be done to reduce the barriers they face. Pragmatically, it is easier to talk to the engaged 'hard to reach' students about the barriers they have overcome and how they can be lowered for others. The second difficulty is that looking at unengagement creates a very messy picture. People may choose not to engage or they may face multiple barriers and belong to multiple 'hard to reach' groups. The lens of 'hard to reach' simplifies this picture, so that we can consider the barriers that are thrown up for people with a particular characteristic. Of course, we need to be careful 
not to forget the intersectionality of these barriers (Crewshaw, 1989), but this lens gives us a useful way in.

\section{Who is the provision for?}

If provision is designed for a certain group of students, it is likely to disengage students who are not in that group. Our interviewees gave examples of student engagement structures being designed for undergraduates and replicated, without thought, for postgraduates. However, we must remember that, even when we design provision for a 'hard to reach' group of students, they may still face significant barriers to participating in it. Transition Mentoring at UCL is designed with widening participation students in mind, to tackle the barrier many of them face of not understanding what is expected of them at university (UCL, 2014 and 2017). When we spoke to UCL's Transition Mentors, they identified barriers to engagement with the scheme with reference to how the participants related to others in their mentor group and to time and money. Widening participation students are the very ones who might lack the time and money to participate. Furthermore, if the groups are facilitated by white, middle-class, engaged students, this might create an environment in which it is harder for widening participation students to relate to other group members.

One of the potential solutions to make our schemes more accessible is to run them in partnership with students. The Transition Mentor scheme is a student-partnership scheme, in which higher-year students make a significant contribution to the running of the scheme. This suggests that, where a scheme is being designed for a particular group of students, it is important, where possible, to partner with students from that group - only they are "legitimate informants on the student experience" (Cook-Sather et al, 2014:16) for members of their group.

\section{Conclusion}

We believe that, if we want as full a picture as possible of how inclusive our practices are, we need to focus on both the characteristics of students and the institution that makes them 'hard to reach'. Though it is clearly the institution's practices that need to change, we cannot, without considering who face barriers to engagement, properly understand them and how to make changes. Focusing on 'hard to reach' groups of students serves as a useful tool for considering inclusivity, reducing the 'messiness' and enabling us to talk to students about the barriers they have faced. However, we need to be careful not to forget the intersectionality between the groups and the way this may affect how barriers are experienced. Finally, it is useful to think carefully about whether provision designed for particular students is appropriate. However, we should not assume that the target groups do not face barriers to engaging with the provision. Ideally, we would work in partnership with students from target 'hard to reach' groups to ensure that the provision best meets their needs.

\section{Reference list}

Cook-Sather, A., Bovill, C. and Felten, P. (2014) Engaging students as partners in learning and teaching: A guide for faculty. San Francisco: John Wiley and Sons.

Crewshaw, K. (1989) 'Demarginalizing the Intersection of Race and Sex: A Black Feminist Critique of Antidiscimination Doctrine, Feminist Theory and Antiractist Politics.' University of Chicago Legal Forum 140, 139-167. Available at: https://philpapers.org/rec/CREDTI (Accessed: 15 May 2017). 
Marie, J., MacKenzie, S., Rowett, S. and Wright, M. (2017) 'Staff Perceptions of 'Hard to Reach.' Journal of Educational Innovation, Partnership and Change, This issue.

UCL (2014) 'Transition at UCL.' Available at: http://www.ucl.ac.uk/transition (Accessed: 15 May 2017).

UCL (2017) 'UCL Access Agreement 2017-2018.' Available at:

https://www.offa.org.uk/agreements/University\%20College\%20London\%201718.pdf (Accessed: 15 May 2017).

\section{Acknowledgements}

Our thanks go to Claudia Balseca, Cristian Gutierrez, Tejas Joshi, Abbie King and Alex Standen, who contributed to the work of the UCL React group and informed our thinking through their discussions with us. 